\title{
A semicontinuous study on the ecotoxicity of atmospheric particles using a versatile aerosol concentration enrichment system (VACES): development and field characterization
}

\author{
Xiaona Shang ${ }^{1}$, Ling Li ${ }^{1,2}$, Xinlian Zhang ${ }^{1}$, Huihui Kang ${ }^{1}$, Guodong Sui ${ }^{1}$, Gehui Wang ${ }^{2}$, Xingnan Ye ${ }^{1}$, Hang Xiao ${ }^{3}$, \\ and Jianmin Chen ${ }^{1,2,3}$ \\ ${ }^{1}$ Shanghai Key Laboratory of Atmospheric Particle Pollution and Prevention (LAP ${ }^{3}$ ), Department of Environmental Science \\ \& Engineering, Institute of Atmospheric Sciences, Fudan University, Shanghai 200438, China \\ ${ }^{2}$ Institute of Eco-Chongming, 3663 N. Zhongshan Rd., Shanghai 200062, China \\ ${ }^{3}$ Institute of Eco-Environment, University of Chinese Academy of Sciences, Beijing 100080, China
}

Correspondence: Jianmin Chen (jmchen@ fudan.edu.cn)

Received: 14 January 2020 - Discussion started: 23 March 2020

Revised: 12 December 2020 - Accepted: 7 January 2021 - Published: 10 February 2021

\begin{abstract}
Oxidative stress can be used to evaluate not only adverse health effects but also adverse ecological effects, but limited research uses eco-toxicological assay to assess the risks posed by particle matters to non-human biomes. One important reason might be that the concentration of toxic components of atmospheric particles is far below the high detection limit of eco-toxic measurement. To solve the rapid detection problem, we extended a versatile aerosol concentration enrichment system (VACES) for ecotoxicity aerosol measurement and firstly used VACES to provide a comparison of ecotoxicity between non-concentrated and concentrated aerosols in ambient air. In this study, the total concentration (number or mass), the concentration of chemical components and the ecotoxicity were all increased by approximately 7 to 10 times in VACES, making the detection of ecotoxicity above the baseline. The comparison of ecotoxicity data and $\mathrm{PM}_{2.5}$ concentration showed that low concentration was not matched with ecotoxicity, although high concentration corresponded to higher ecotoxicity. In addition, the higher saturation temperature in VACES caused a loss of particulate matter, of which nitrate accounted for about $18 \%$.
\end{abstract}

\section{Introduction}

Currently, most toxicological studies focus on discovering the relationship between particulate matter and the morbidity or mortality of organisms (e.g., Vincent et al., 2001; Cox et al., 2016; Miri et al., 2018) or on exploring toxic mechanisms by exposure experiments (e.g., Magnani et al., 2016; Huang et al., 2017; Rychlik et al., 2019). However, the measurement of ecotoxicity data is rarely available because of technical limitations. For instance, it requires a long detection time due to animal and plant reproduction or cell cultivation (National Research Council, 2006), but the concentration and chemical composition of particulate matter in the atmosphere continue to change over time, especially during severe pollution (Shang et al., 2018a, b). Thereby, a short analyzing time is quite important.

To solve this problem, photobacteria (e.g., Photobacterium phosphoreum are utilized in the ecotoxicity study of atmospheric particles because the detection was rapid (e.g., within $15 \mathrm{~min}$ ) and the cultivation period is only $5 \mathrm{~min}$ (Jing et al., 2019). The method of measuring ecotoxicity using photobacterium bioluminescence inhibition bioassay has long been routinely applied and standardized for water and soil research (Water quality, 2007). It had been reported that the Vibrio fischeri EC50 (median effective concentration) significantly correlated to rat and mouse LD50 (the lethal dose for $50 \%$ of the animals tested) values, indicating the reliability of photobacterium-based ecotoxicity as- 
say (Fort, 1992; Kaiser et al., 1994). Recently, photobacteria have also been often used to assess the ecotoxicity of particulate matter and chemical components in the atmosphere. For instance, Turóczi et al. (2012) used Vibrio fischeri to study the ecotoxicity of $\mathrm{PM}_{10}$. This study directly evaluated the overall ecotoxicity of particles from different sources and seasons. Tositti et al. (2018) developed an ecotoxicity detection method using Vibrio fischeri and found that ecotoxicity was closely related to the compositions of $\mathrm{PM}_{10}$. Wang et al. (2016) demonstrated that the $\mathrm{PM}_{2.5}$ components analyzed by Photobacterium Phosphoreum T3 bioassay were ecologically toxic. Eck-Varanka et al. (2019) analyzed the ecotoxicity of size-fractionated particles using Vibrio fischeri. Such literature proved the feasibility of the photobacterium-based method in assessing the ecological toxicity of atmospheric particulate matter. However, the detection limit of ecotoxicity using photobacteria is high. For example, in Jing's research, samples with a light inhibition rate of less than $20 \%$ were considered to be non-toxic due to the impact of normal bacterium fluctuations, whereas the concentration of atmospheric aerosols is usually far lower than that required for eco-toxic assay in the case of a short sampling time (e.g., $1 \mathrm{~h}$ ), which means a longer sampling time is required. Nevertheless, long-term sampling may lead to a large loss of volatile substances or chemical reactions in the particles, subsequently resulting in large errors in ecotoxicity analysis (von der Weiden et al., 2009).

In this respect, aerosol enrichment techniques have been developed and applied to increase aerosol concentrations to meet ecotoxicity detection limits. Among them, the versatile aerosol concentrator enrichment system (VACES) originally developed by Sioutas et al. (1999) is effectively used to concentrate ambient particles. Since then, it has been widely used for laboratory and field measurements of particulate matter (De Vizcaya-Ruiz et al., 2006; Steenhof et al., 2011; Plummer et al., 2012; Loxham et al., 2013) because the physical and chemical properties do not change after becoming concentrated (Kim et al., 2001a, b; Wang et al., 2013). It has also been extended to combine various chemical and physical analyses of particulate matter (e.g., gases, water-soluble ions, heavy metals, polycyclic aromatic hydrocarbons, cloud condensation nuclei, etc.) (Jung et al., 2010; Freney et al., 2006; Pakbin et al., 2011; Zhao et al., 2005; Dameto et al., 2019). In addition, VACES has been applied to determine the relationship between particulate matter and health effects based on exposure experiments (Klocke et al., 2017; Ljubimova et al., 2018). Nevertheless, although VACES was originally developed to provide technical support for ecotoxicity detection, there is no direct measurement data to show the change in ecotoxicity between ambient particles and VACES particles.

Therefore, according to the previous design, by optimizing technical parameters, we modified and further developed VACES to be integrated into the ecotoxicity measurements, verified the enrichment effect on physiochemical concentration and ecotoxicity in laboratory and field studies, and also investigated the relationship between ecotoxicity and particulate masses.

\section{Methodology}

\subsection{Design of VACES}

VACES used a saturation and condensation system to rapidly grow particles into supermicron droplets which were then concentrated by a virtual impactor (VI). A detailed description of the design of VACES is available in previous studies (e.g., Kim et al., 2001a, b). Briefly, when the airflow was sucked into a water tank filled with deionized water (defined as a saturator) with a $U$-shaped heating tube inside, the particles became supersaturated. A tube was fixed above the outlet of the saturator, and a copper tube coil was tightly wound on the outside to provide fast condensation conditions. A chiller (Bilon, China) filled with ethanol (80\%, Hushi, China) was cooled through the coil. The condensed aerosols were drawn up to a virtual impactor where particle concentration by size was concentrated to a desired level by changing the ratio of the major-to-minor air flow controlled by a mass flow controller (MFC; D08-4F, Sevenstar, China).

\subsection{Sampling}

Sampling was conducted for several experiments, including a laboratory performance test, a field performance test, discontinuous sample collection and continuous sample collection. The performance test in this study used the enrichment factor (EF) defined as the ratio of concentrated (VACES) to non-concentrated (ambient) particle concentration and the enrichment efficiency (EE) defined as the ratio of the concentrated concentration to 10 times the non-concentrated concentration as a standard. The closer the EF and EE are to $10 \%$ and $100 \%$, respectively, the better the enrichment effect of VACES. The instrument operating parameters (major air flow, minor air flow, condensation temperature and saturation temperature) were defined as the optimal parameters when the best enrichment effect was obtained. In the laboratory performance test, an atomizer (model 9302, TSI, USA) was used to atomize polystyrene latex (PSL; Thermo Fisher Scientific, USA) to produce 200, 300, 500 and $700 \mathrm{~nm}$ particles, respectively (Fig. 1). In one case, after drying the generated PSL particles (Nafion tube, MD-700, Perma Pure, USA), we set the corresponding voltage through a differential mobility analyzer (DMA; model 3081, TSI, USA) for screening, and then they entered the condensation particle counter (CPC; model 3775, TSI, USA) at a flow rate of $0.3 \mathrm{~L} \mathrm{~min}^{-1}$ for counting. In the other case, PSL particles were introduced into VACES to obtain 10 times the concentration, and then the concentrations were calculated by the system of DMA and CPC after drying. We use four data sets (number and mass) of PSL particles with and without enrichment to draw the EF calibration line. In comparison, the field performance 


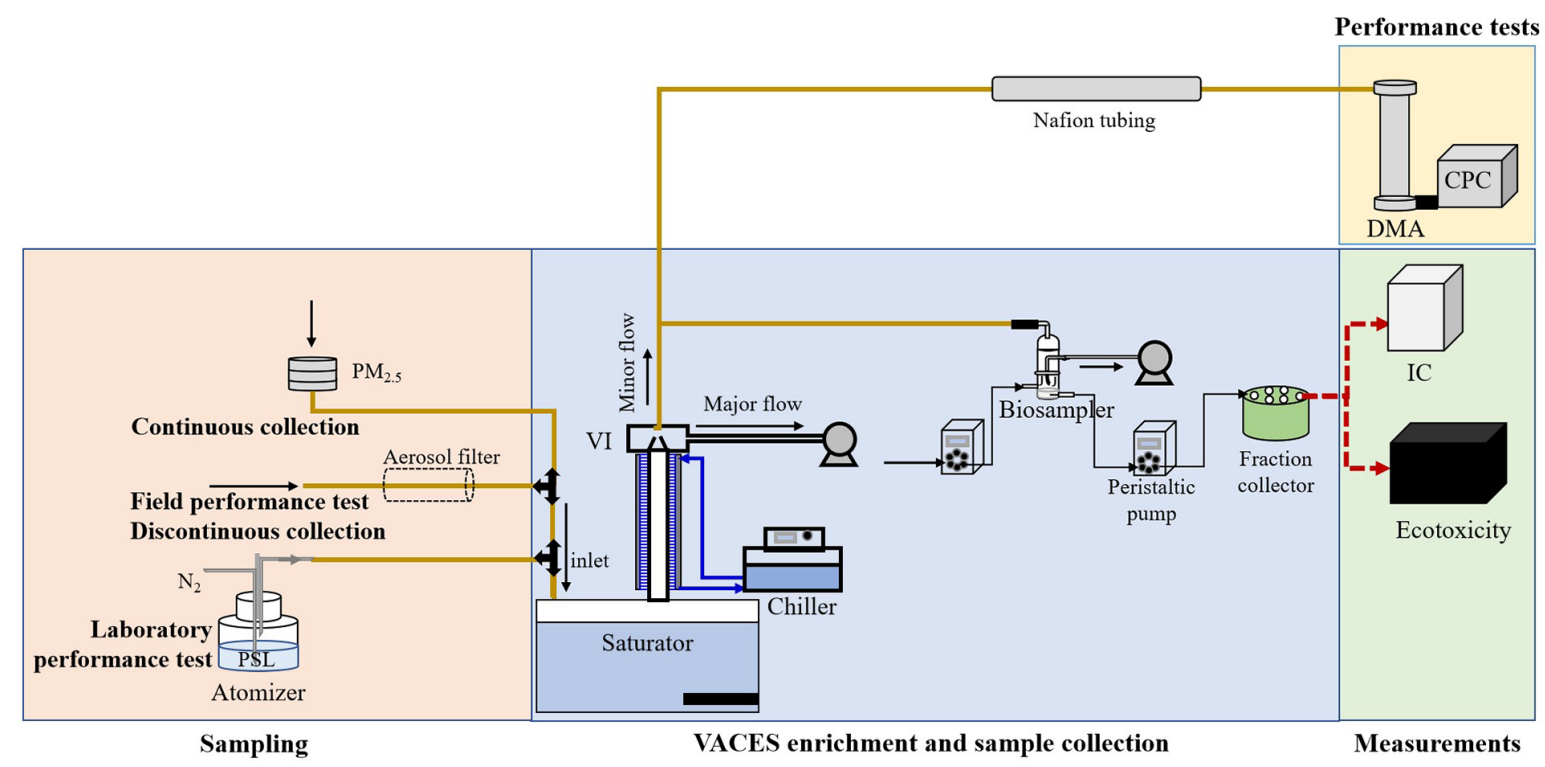

Figure 1. Setup for performance test and field sample collection. The experiments referring to VACES including laboratory and field performance tests, discontinuous and continuous sample collections, and their measurements. In the laboratory performance test, air flow passed through the atomizer, VACES (saturator-condensation tube-virtual impactor), Nafion tubing, DMA and CPC successively. For the two field performance tests, in the first one, air flow passed through VACES, Nafion tubing, DMA and CPC successively, and in the second, one air flow passed through the aerosol filter, VACES, Nafion tubing, DMA and CPC successively. During the discontinuous sample collection, particles followed the flow line of VACES to the biosampler. For the continuous sample collection, particles were collected from the PM 2.5 sampler, VACES and biosampler to the fraction collector. Both types of collected samples were used for online ionic measurement by ion chromatography and online eco-toxic assay by a photobacterium acute toxicity analyzer (an integrated instrument with automatic operation controlling by a programming).

test was similar to the laboratory test. The only difference was the replacement of PSL particles with ambient particles $(<1.0 \mu \mathrm{m})$. In addition, during the field performance test, an aerosol filter (ETA Filters, USA) was installed at the inlet of the saturator to remove ambient particles to study the formation of particles in VACES (Fig. 1; the dash line marks the filter location). Then, if no or few particles were observed in $\mathrm{CPC}$, the impact of particle formation in VACES could be excluded or ignored.

In the performance test, we determined the optimal parameters (as defined above) of VACES. Then, we successively carried out discontinuous and continuous VACES particle collection on the sixth floor of the Environmental Science and Engineering Department of Fudan University in Shanghai. We opened the inlet to the ambient air, in which particles were sucked into the saturator at a major flow rate and increased in concentration at a minor flow rate (Kim et al., 2001a). VACES particles were collected in $5 \mathrm{~mL}$ of deionized water through a biosampler (SKC, USA) for $30 \mathrm{~min}$ and $1 \mathrm{~h}$. In order to study the physiochemical and ecotoxicity differences between VACES particles and environmental particles, we switched the inlet of the biosampler to ambient air after VACES particles were collected; that is to say, $30 \mathrm{~min}$ $(1 \mathrm{~h})$ VACES samples then $30 \mathrm{~min}(1 \mathrm{~h})$ environmental samples. From 23 October to 11 December 2019, we obtained a total of 10 sets of 30 min samples and 10 sets of $1 \mathrm{~h} \mathrm{sam}$ ples. Therefore, due to time discontinuity, sampling was defined as a discontinuous collection. In contrast, in the continuous sample collection process, we added a $\mathrm{PM}_{2.5}$ sampler (PM-100, Wuhan Tianhong, China) to the inlet of VACES. To achieve continuous VACES particle collection, we added a peristaltic pump (BT100-4, HUXI, China) to the front of the biosampler to pump in deionized water, and connected the outlet of the biosampler to another peristaltic pump to evacuate the sample into an automatic fraction collector (BS40A, HUXI, China). Pumping in and out was performed at a scheduled time (59 min sleep mode and 1 min work mode) and volume $(5 \mathrm{~mL})$. However, the continuous collection of ambient particles was performed by a $\mathrm{PM}_{2.5}$ cyclone (Met one Instruments, USA) at a flow rate of $5 \mathrm{~L} \mathrm{~min}^{-1}$ and on a $47 \mathrm{~mm}$ Teflon filter (Whatman, USA). The filter sampling time is $8 \mathrm{~h}$ to meet the detection limit of water-soluble ions. In the end, we collected 88 VACES samples and 11 simultaneous ambient samples from 18 to 31 December 2019. Note that the filter samples were extracted in $10 \mathrm{~mL}$ deionized water via 20 min sonication and $<34^{\circ} \mathrm{C}\left(<34^{\circ} \mathrm{C}\right.$ within filter bottle and $45^{\circ} \mathrm{C}$ out of filter bottle) heating conditions. 


\subsection{Measurements}

All samples were filtered using $0.22 \mu \mathrm{m}$ pore size filters (Collins, China) and $10 \mathrm{~mL}$ sterile syringes (KDL, China). Then, ecotoxicity assay and water-soluble ion measurements were conducted immediately. Regarding the ecotoxicity assay, Jing et al. (2019) provided detailed information. In brief, $100 \mu \mathrm{L}$ of the prepared bacterial suspension was pipetted into cuvettes to measure the luminous intensity as the baseline. After, the initial luminous intensity was recorded after adding $100 \mu \mathrm{L}$ of sample. In $15 \mathrm{~min}$, the luminous intensity was recorded again. After subtracting blank intensity tested using $\mathrm{NaCl}$ solution (3\%), the light inhibition rate of VACES and ambient particles was calculated according to the international standard procedures (Water quality, 2007). All samples were tested in triplicate and averaged in the present study. To ensure the enrichment effect of the VACES system, we also detected water-soluble ions of both ambient and VACES samples collected during the continuous sampling period using ion chromatography (940 Professional IC Vario, Metrohm, Swiss) integrated with an autosampler (863 Compact Autosampler, Metrohm, Swiss). Moreover, the atmospheric $\mathrm{PM}_{2.5}$ concentration was monitored in a nearby statecontrolled site (Liangcheng, Hongkou, Shanghai, China).

\section{Results and discussion}

\subsection{Performance test of VACES}

The optimization of VACES is to achieve 10-fold enrichment of ambient aerosol concentration mainly through modulating temperatures of the saturator and chiller, the major air flow, the minor air flow, and their flow ratio. By switching air pathways between ambient and VACES and comparing their number and mass concentrations observed in a scanning mobility particle sizer (SMPS; DMA+CPC), we established optimal parameters for the desired EF (10) and EE (100\%). Results showed that the EF of 10 could be achieved for particles larger than $\sim 30 \mathrm{~nm}$ as setting the optimal parameters of $-19 \pm 1{ }^{\circ} \mathrm{C}$ condensation temperature, $45 \pm 2{ }^{\circ} \mathrm{C}$ water bath temperature, $50 \pm 1 \mathrm{~L} \mathrm{~min}^{-1}$ major air flow and $1 / 10$ minorto-major air flow ratio. It should be noted that after mixing with ambient aerosol stream (ambient temperature was no more than $24^{\circ} \mathrm{C}$ during experiment period), the saturation temperature was decreased to $31^{\circ} \mathrm{C}$ or lower, thereby reducing the loss of volatile and semi-volatile compounds (Pirhadi et al., 2020). The corresponding EE ranged from $75 \%$ to $100 \%$ in different size ranges as listed in Table 1 . The highest EE was obtained in the size range of $30-100 \mathrm{~nm}$, very close to $100 \%$.

For the laboratory performance test, the number concentrations of VACES and ambient PSL particles were alternatively measured six times in parallel. The EF calibration line was plotted by the number concentration in four sizes

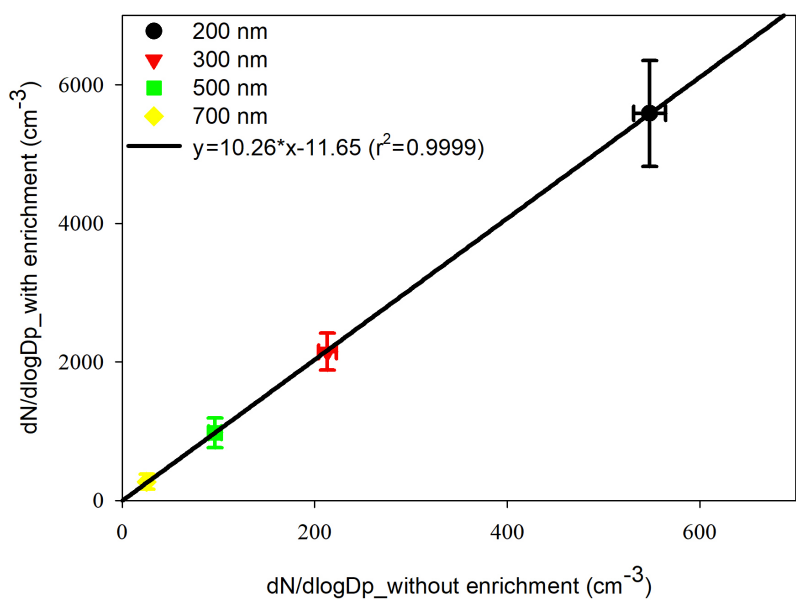

Figure 2. Calibration of enrichment factor of VACES system using polystyrene latex (PSL) aerosol reagent $200-700 \mathrm{~nm}$ in size. Error bars are the standard deviation of six parallel measurements.

of VACES particles against ambient particles. It showed a quite high correlation coefficient $\left(r^{2}=0.9999\right)$, and the EF of VACES was 10 approximately (Fig. 2).

Similarly, we measured the number and mass concentrations of particulate matter in the field performance test. When the concentration coordinate value of VACES was set to 10 times that of ambient air, the two curves almost coincided for particle size greater than $25 \mathrm{~nm}$ (Fig. 3a and b), indicating that the $\mathrm{EE}$ was close to $100 \%$. In addition, the investigation of particle formation in VACES showed that the maximum of newly formed particles in size was only $\sim 1 \%$ of the total number and mass concentration (Fig. $3 \mathrm{c}$ and d), which could be neglected. Moreover, the mass peak always appeared in the same particle size with a similar concentration, which indicated that it was most likely to be a water vapor peak and not a newly formed particle in the system.

\subsection{Ecotoxicity variation in VACES particles}

The study evaluated the ecotoxicity by the light inhibition rate of photobacteria; the higher the value is, the higher the ecotoxicity is. The light inhibition rate was calculated by multiplying by 100 the ratio of the changes in fluorescence intensity (between treated and untreated medium) to the intensity of untreated medium. The untreated medium meant only bacteria in medium, and treated medium corresponded to a sample adding in bacteria medium. Discontinuous sampling was operated under $\mathrm{PM}_{2.5}$ concentrations ranging from 21 to $187 \mu \mathrm{g} \mathrm{m}^{-3}$. During the sampling period, the photobacterium light inhibition rate of almost all ambient samples was lower than the baseline (20\%). On the contrary, the rate of all VACES samples was higher than $20 \%$ (Fig. 4a and b). Note that since bacteria are sensitive to environmental condition, it is difficult to determine whether the sample is non-toxic or toxic as the inhibition rate is lower than the 
Table 1. Enrichment efficiency of ambient aerosols in VACES at different size ranges.

\begin{tabular}{lrrrrr}
\hline Particle size & $\begin{array}{r}\text { Condensation } \\
\left(-19 \pm 11^{\circ} \mathrm{C}\right)\end{array}$ & $\begin{array}{r}\text { Saturation } \\
\left(-45 \pm 2{ }^{\circ} \mathrm{C}\right)\end{array}$ & $\begin{array}{r}\text { Major flow } \\
\left(50 \pm 1 \mathrm{~L} \mathrm{~min}^{-1}\right)\end{array}$ & $\begin{array}{r}\text { Minor-to-major } \\
\text { flow ratio }(1 / 10)\end{array}$ & Total \\
\hline $30-50 \mathrm{~nm}$ & $99 \% \pm 22 \%$ & $85 \% \pm 10 \%$ & $97 \% \pm 13 \%$ & $97 \% \pm 13 \%$ & $98 \% \pm 8 \%$ \\
$50-100 \mathrm{~nm}$ & $100 \% \pm 12 \%$ & $85 \% \pm 5 \%$ & $99 \% \pm 9 \%$ & $99 \% \pm 9 \%$ & $91 \% \pm 6 \%$ \\
$100-200 \mathrm{~nm}$ & $85 \% \pm 11 \%$ & $82 \% \pm 3 \%$ & $78 \% \pm 12 \%$ & $80 \% \pm 12 \%$ & $79 \% \pm 3 \%$ \\
$200-1000 \mathrm{~nm}$ & $\mathrm{NA}$ & $\mathrm{NA}$ & $\mathrm{NA}$ & $\mathrm{NA}$ & $75 \% \pm 10 \%$ \\
\hline
\end{tabular}

* NA: not available.

(a)

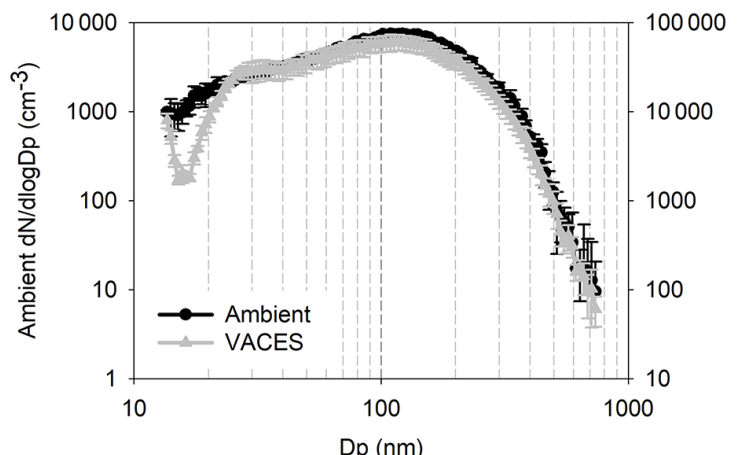

(c)

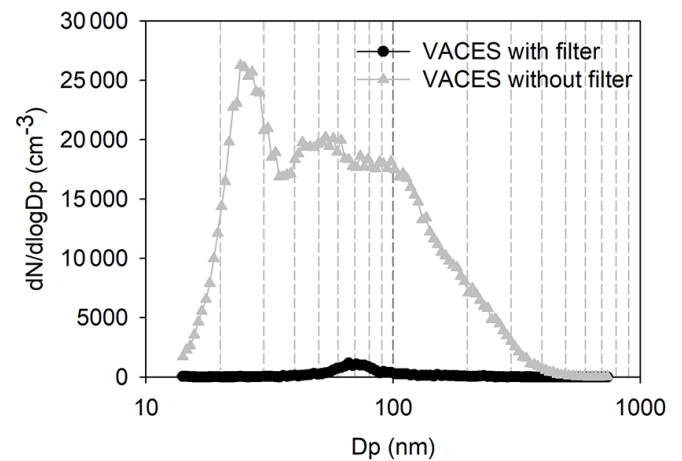

(b)

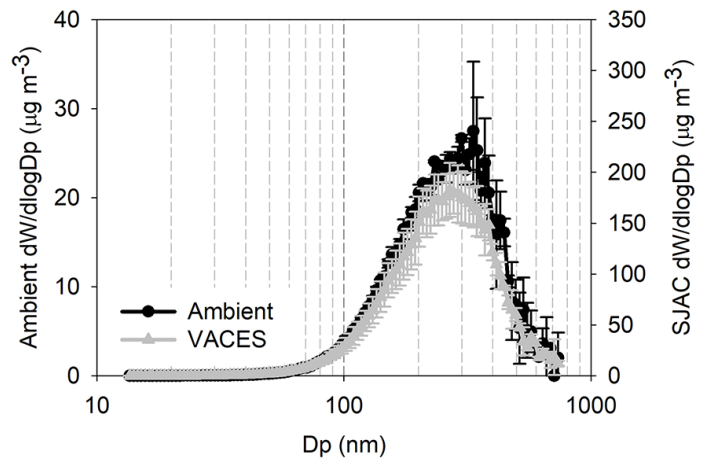

(d)

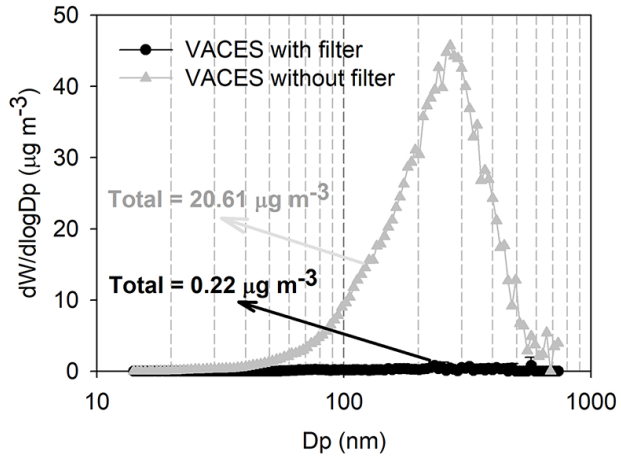

Figure 3. Particle (a, c) number and (b, d) mass size distribution in ambient and VACES systems. The error bar is standard deviation of three parallel experiments.

baseline. It implied that the increase in ecotoxicity caused by the increase in particulate concentration could avoid the inaccurate assessment of particulate ecotoxicity in the range below the baseline. In addition, when the concentration was low, the change in the light inhibition rate of ambient particles did not match the concentration of environmental $\mathrm{PM}_{2.5}$. However, under high concentrations of $\mathrm{PM}_{2.5}$, they matched better. During the continuous sampling period, $\mathrm{PM}_{2.5}$ concentrations varied from 14 to $107 \mu \mathrm{g} \mathrm{m}^{-3}$. The light inhibition of both ambient and VACES particles exhibited similar trends to the change in $\mathrm{PM}_{2.5}$ concentration (a strong positive correlation, $r^{2}>0.7$ ) (Fig. 5). Note that as the data points of low $\mathrm{PM}_{2.5}$ concentration were removed, the correlation coefficient increased. Both experiments indicated that as the concentration of $\mathrm{PM}_{2.5}$ decreased, the impact of concentration on ecotoxicity might be weakened, and the ecotoxicity may be caused mainly by the toxic chemical components in the particles (Akhtar et al., 2014). In this regard, the effects of key toxic components on ecotoxicity changes need to be further studied using VACES.

The change in EF was roughly the reversal of the trend of the light inhibition rate of the ambient and VACES particles (Fig. 4). The main reason was that the increase in the light inhibition rate of VACES particles was lower than that of the ambient particles at high $\mathrm{PM}_{2.5}$ concentrations. Comparing the EF changes in chemical components, it was found that when the ratio of light inhibition rate of VACES to ambient particles decreased, the EF corresponding to nitrate also decreased (Fig. 6). It showed that under high $\mathrm{PM}_{2.5}$ concentrations, the EE of VACES for high-concentration nitrate was reduced, which was probably attributed to the loss of nitrate in VACES at a higher saturation temperature (about $7^{\circ}$ higher than the ambient air). According to calculations, among the VACES particle concentration loss (average of $20.1 \%$ dur- 
(a)

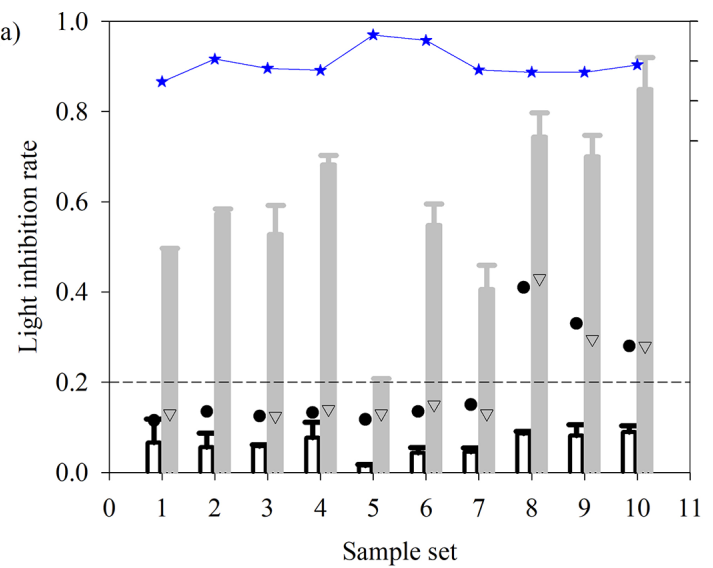

(b)

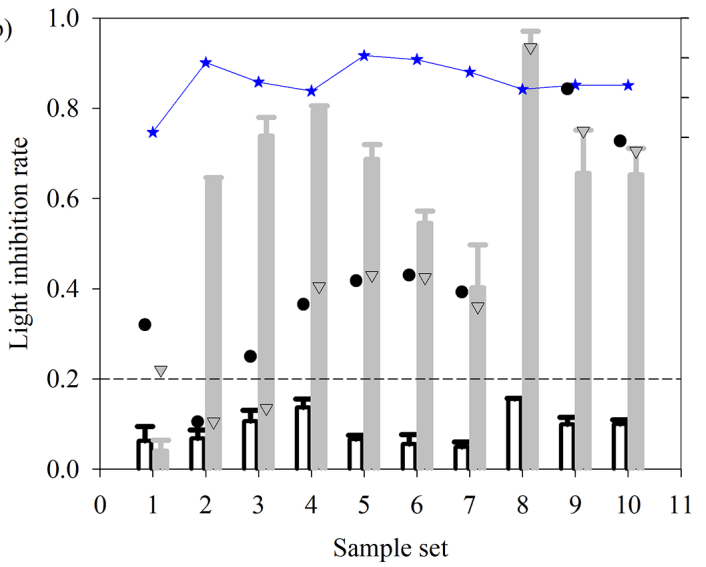

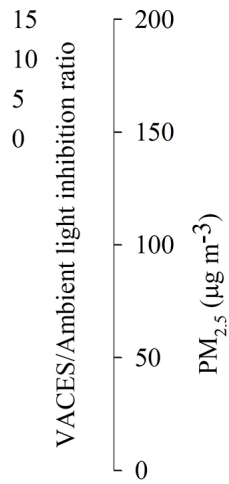

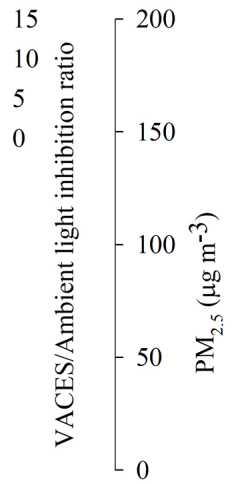

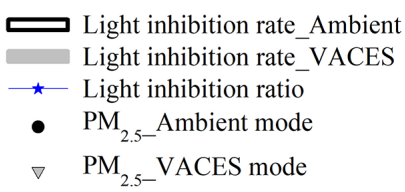

Ambient

$\nabla \quad \mathrm{PM}_{2.5-}$ VACES mode

Figure 4. Comparison of light inhibition rate and ratio of ambient and VACES particles with ambient $\mathrm{PM}_{2.5}$ concentration based on (a) hourly and (b) 30 min discontinuous sample collection during 23 October-11 December 2019 in Shanghai, China. Baseline reflected the accuracy of photobacterium-based ecotoxicity assay method, and below the baseline, the accuracy is low.

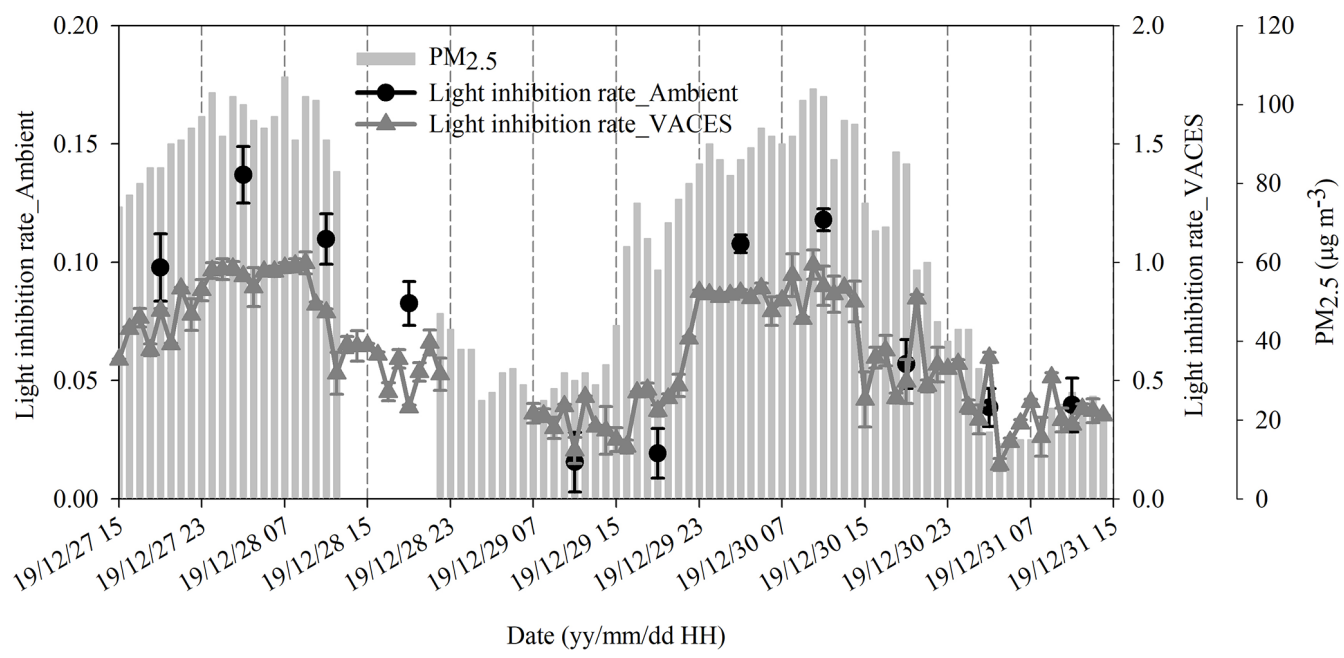

Figure 5. Comparison of light inhibition rate between ambient and VACES particles based on continuous sampling of VACES and ambient particles. VACES samples were collected hourly and ambient filter samples were collected every $8 \mathrm{~h}$. The $\mathrm{PM}_{2.5} \mathrm{Concentration}$ data were collected hourly from a nearby monitoring center (online data). 


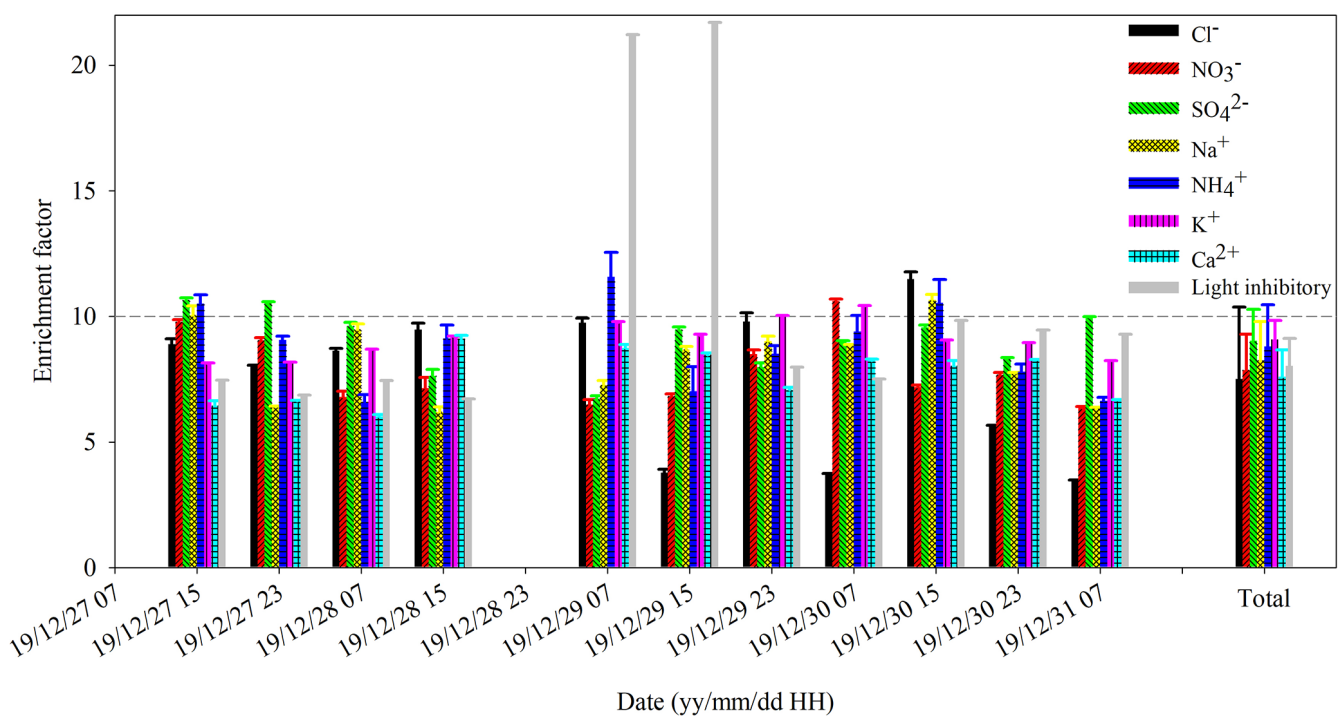

Figure 6. Enrichment factors of chemical compositions and light inhibition of $\mathrm{PM}_{2.5}$ during the continuous sampling period. The EF was calculated by the ratio of chemical concentrations of VACES to ambient particles. The component concentration of VACES particles was $1 \mathrm{~h}$ per sample, and the concentration of ambient particles was $8 \mathrm{~h}$ per sample. For the ratio, we averaged the concentrations of VACES samples every $8 \mathrm{~h}$ to correspond to that of ambient samples.

ing entire experiment period), nitrate accounted for $18.0 \%$. Therefore, under the premise of providing sufficient water vapor, reducing the saturation temperature or reducing the deviation from the ambient temperature was an important way to improve the enrichment effect of VACES.

\section{Conclusions and implications}

To achieve detection limits for atmospheric particulate ecotoxicity, a versatile aerosol concentration enrichment system (VACES) was extended to be integrated with ecotoxicity measurements. The VACES was developed to increase particle concentrations by about 7-10 times under the conditions of chiller temperature $\left(-19 \pm 1^{\circ} \mathrm{C}\right)$, saturator temperature $\left(45 \pm 2{ }^{\circ} \mathrm{C}\right.$; supersaturation temperature was less than $\left.31{ }^{\circ} \mathrm{C}\right)$, major air flow $\left(50 \pm 1 \mathrm{~L} \mathrm{~min}^{-1}\right)$ and minor-to-major flow ratio $(1 / 10)$. We conducted discontinuous and continuous sample collections to analyze the ecotoxicity of VACES and ambient particles at half-hour and $1 \mathrm{~h}$ time resolutions, respectively. It was found that the ecotoxicity of almost all ambient samples below the detection baseline like the ambient $\mathrm{PM}_{2.5}$ concentration varied from 14 to $187 \mu \mathrm{g} \mathrm{m}^{-3}$. After enrichment, however, the ecotoxicity was clearly detected for almost all samples, proving the feasibility of the integrated system on rapid ecotoxicity assay. In addition, by comparing the change in the ambient $\mathrm{PM}_{2.5}$ concentration with the light inhibition rate of ambient and VACES particles, it was found that as the concentration of $\mathrm{PM}_{2.5}$ decreased, the correlation between the $\mathrm{PM}_{2.5}$ concentration and the light inhibition rate was significantly weakened. It meant that at low concentrations of particulate matter, the impact of concentra- tion on ecotoxicity was greatly reduced, and the interference with ecotoxicity might be the change in toxic components. Moreover, during the high $\mathrm{PM}_{2.5}$ concentration period, the ecotoxicity of VACES particles and the EF were significantly weakened or reduced due to the loss of nitrate in a relatively high-temperature VACES system, which provided guidance for improving the enrichment effect of VACES.

Data availability. Data are available by contacting the corresponding author.

Author contributions. XS and JC designed the experiments. XS performed the experiment, analyzed the data and wrote the paper. XZ, HK, LL, GS and XY assisted with bio-toxicity and enrichment experiments. GW and HX helped by providing suggestions in paper revisions.

Competing interests. The authors declare that they have no conflict of interest.

Acknowledgements. This work was funded by National Natural Science Foundation of China (grant nos. 21527814, 91843301, 91743202, 22006021).

Financial support. This research has been supported by the National Natural Science Foundation of China (grant nos. 21527814, 91843301, 91743202, and 22006021). 
Review statement. This paper was edited by Paolo Laj and reviewed by two anonymous referees.

\section{References}

Akhtar, U. S., Rastogi, N., McWhinney, R. D., Urch, B., Chow, C. W., Evans, G. J., and Scott, J. A: The combined effects of physicochemical properties of size-fractionated ambient particulate matter on in vitro toxicity in human A549 lung epithelial cells, Toxicol. Rep., 1, 145-156, 2014.

Cox, B., Gasparrini, A., Catry, B., Fierens, F., Vangronsveld, J., and Nawrot, T. S.: Ambient Air Pollution-related Mortality in Dairy Cattle: Does It Corroborate Human Findings?, Epidemiology, 27, 779-786, 2016.

Dameto de España, C., Steiner, G., Schuh, H., Sioutas, C., and Hitzenberger, R.: Versatile aerosol concentration enrichment system (VACES) operating as a cloud condensation nuclei (CCN) concentrator: development and laboratory characterization, Atmos. Meas. Tech., 12, 4733-4744, https://doi.org/10.5194/amt12-4733-2019, 2019.

De Vizcaya-Ruiz, A., Gutiérrez-Castillo, M. E., Uribe-Ramirez, M., Cebrián, M. E., Mugica-Alvarez, V., Sepúlveda, J., Rosas, I., Salinas, E., Garcia-Cuéllar, C., Martínez, F., Alfaro-Moreno, E., Torres-Flores, V., Osornio-Vargas, A., Sioutas, C., Fine, P. M., Singh, M., Geller, M. D., Kuhn, T., Miguel, A. H., EigurenFernandez, A., Schiestl, R. H., Reliene, R., and Froines, J.: Characterization and in vitro biological effects of concentrated particulate matter from Mexico City, Atmos. Environ., 40, 583-592, 2006.

Eck-Varanka, B., Hubai, K., Horváth, E., Kováts, N., Teke, G., and Tóth, Á.: Assessing Ecotoxicity of Size-fractionated Airborne Particulate Matter, E3S Web Conf., 99, 04010, https://doi.org/10.1051/e3sconf/20199904010, 2019.

Fort, F.: Correlation of Microtox EC, with mouse LD, Toxicol. In Vitro, 5, 73-82, 1992.

Freney, E. J., Heal, M. R., Donovan, R. J., Mills, N. L., Donaldson, K., Newby, D. E., Fokkens, P. H. B., and Cassee, F. R.: A singleparticle characterization of a mobile Versatile Aerosol Concentration Enrichment System for exposure studies, Part Fibre Toxicol., 3, 8-8, 2006.

Huang, Q., Chi, Y., Deng, J., Liu, Y., Lu, Y., Chen, J., and Dong, S.: Fine particulate matter 2.5 exerted its toxicological effect by regulating a new layer, long non-coding RNA, Sci. Rep.-UK, 7, $1-9,2017$.

Jing, W., Liu, Q., Wang, M., Zhang, X., Chen, J., Sui, G., and Wang, L.: A method for particulate matter $2.5\left(\mathrm{PM}_{2.5}\right)$ biotoxicity assay using luminescent bacterium, Ecotox. Environ. Safe., 170, 796803, 2019.

Jung, H., Arellanes, C., Zhao, Y., Paulson, S., Anastasio, C., and Wexler, A.: Impact of the Versatile Aerosol Concentration Enrichment System (VACES) on Gas Phase Species, Aerosol Sci. Tech., 44, 1113-1121, 2010.

Kaiser, K. L., McKinnon, M. B., and Fort, F. L.: Interspecies toxicity correlations of rat, mouse and Photobacterium phosphoreum, Environ. Toxicol. Chem., 13, 1599-1606, 1994.

Kim, S., Jaques, P. A., Chang, M., Barone, T., Xiong, C., Friedlander, S. K., and Sioutas, C.: Versatile aerosol concentration enrichment system (VACES) for simultaneous in vivo and in vitro evaluation of toxic effects of ultrafine, fine and coarse ambient particles Part II: Field evaluation, J. Aerosol Sci., 32, 1299-1314, 2001a.

Kim, S., Jaques, P. A., Chang, M., Froines, J. R., and Sioutas, C.: Versatile aerosol concentration enrichment system (VACES) for simultaneous in vivo and in vitro evaluation of toxic effects of ultrafine, fine and coarse ambient particles Part I: Development and laboratory characterization, J. Aerosol Sci., 32, 1281-1297, $2001 b$.

Klocke, C., Allen, J. L., Sobolewski, M., Mayer-Pröschel, M., Blum, J. L., Lauterstein, D., Zelikoff, J. T., and Cory-Slechta, D. A.: Neuropathological Consequences of Gestational Exposure to Concentrated Ambient Fine and Ultrafine Particles in the Mouse, Toxicol. Sci., 156, 492-508, 2017.

Ljubimova, J. Y., Braubach, O., Patil, R., Chiechi, A., Tang, J., Galstyan, A., Shatalova, E. S., Kleinman, M. T., Black, K. L., and Holler, E.: Coarse particulate matter $\left(\mathrm{PM}_{2.5-10}\right)$ in Los Angeles Basin air induces expression of inflammation and cancer biomarkers in rat brains, Sci. Rep.-UK, 8, 1-11, 2018.

Loxham, M., Cooper, M. J., Gerlofs-Nijland, M. E., Cassee, F. R., Davies, D. E., Palmer, M. R., and Teagle, D. A. H.: Physicochemical Characterization of Airborne Particulate Matter at a Mainline Underground Railway Station, Environ. Sci. Technol., 47, 36143622, 2013.

Magnani, N. D., Muresan, X. M., Belmonte, G., Cervellati, F., Sticozzi, C., Pecorelli, A., Miracco, C., Marchini, T., Evelson, P., and Valacchi, G.: Skin Damage Mechanisms Related to Airborne Particulate Matter Exposure, Toxicol. Sci., 149, 227-236, 2016.

Miri, M., Alahabadi, A., Ehrampush, M. H., Rad, A., Lotfi, M. H., Sheikhha, M. H., and Sakhvidi, M. J. Z.: Mortality and morbidity due to exposure to ambient particulate matter, Ecotoxicol. Environ. Saf., 165, 307-313, 2018.

National Research Council: Toxicity Testing for Assessment of Environmental Agents: Interim Report, The National Academies Press, Washington, DC, USA, 2006.

Pakbin, P., Ning, Z., Eiguren-Fernandez, A., and Sioutas, C.: Modification of the Versatile Aerosol Concentration Enrichment System (VACES) for conducting inhalation exposures to semivolatile vapor phase pollutants, J. Aerosol Sci., 42, 555-566, 2011.

Pirhadi, M., Mousavi, A., Taghvaee, S., Shafer, M. M., and Sioutas, C.: Semi-volatile components of $\mathrm{PM}_{2.5}$ in an urban environment: Volatility profiles and associated oxidative potential, Atmos. Environ., 223, 117197, https://doi.org/10.1016/j.atmosenv.2019.117197, 2020.

Plummer, L. E., Ham, W., Kleeman, M. J., Wexler, A., and Pinkerton, K. E.: Influence of Season and Location on Pulmonary Response to California's San Joaquin Valley Airborne Particulate Matter, J. Toxicol. Env. Heal. A, 75, 253-271, 2012.

Rychlik, K. A., Secrest, J. R., Lau, C., Pulczinski, J., Zamora, M. L., Leal, J., Langley, R., Myatt, L. G., Raju, M., Chang, R. C., Li, Y., Golding, M. C., Rodrigues-Hoffmann, A., Molina, M. J., Zhang, R., and Johnson, N. M.: In utero ultrafine particulate matter exposure causes offspring pulmonary immunosuppression, $\mathrm{P}$. Natl. Acad. Sci. USA, 116, 3443-3448, 2019.

Shang, X., Lee, M., Han, J., Kang, E., Kim, S. W., Gustafsson, Ö., and Chang, L.: Identification and Chemical Characteristics of Distinctive Chinese Outflow Plumes Associated with Enhanced 
Submicron Aerosols at the Gosan Climate Observatory, Aerosol Air Qual. Res., 18, 330-342, 2018a.

Shang, X., Zhang, K., Meng, F., Wang, S., Lee, M., Suh, I., Kim, D., Jeon, K., Park, H., Wang, X., and Zhao, Y.: Characteristics and source apportionment of fine haze aerosol in Beijing during the winter of 2013, Atmos. Chem. Phys., 18, 2573-2584, https://doi.org/10.5194/acp-18-2573-2018, 2018 b.

Sioutas, C., Kim, S., and Chang, M.: Development and Evaluation of a Prototype Ultrafine Particle Concentrator, J. Aerosol Sci., 30, 1001-1017, 1999.

Steenhof, M., Gosens, I., Strak, M., Godri, K. J., Hoek, G., Cassee, F. R., Mudway, I. S., Kelly, F. J., Harrison, R. M., Lebret, E., Brunekreef, B., Janssen, N. A. H., and Pieters, R. H. H.: In vitro toxicity of particulate matter (PM) collected at different sites in the Netherlands is associated with PM composition, size fraction and oxidative potential - the RAPTES project, Part Fibre. Toxicol., 8, 1-15, 2011.

Tositti, L., Brattich, E., Parmeggiani, S., Bolelli, L., Ferri, E., and Girotti, S.: Airborne particulate matter biotoxicity estimated by chemometric analysis on bacterial luminescence data, Sci. Total Environ., 640, 1512-1520, 2018.

Turóczi, B., Hoffer, A., Tóth, Á., Kováts, N., Ács, A., Ferincz, Á., Kovács, A., and Gelencsér, A.: Comparative assessment of ecotoxicity of urban aerosol, Atmos. Chem. Phys., 12, 7365-7370, https://doi.org/10.5194/acp-12-7365-2012, 2012.

Vincent, R., Kumarathasan, P., Goegan, P., Bjarnason, S. G., Guenette, J., Berube, D., Adamson, I. Y., Desjardins, S., Burnett, R. T., Miller, F. J., and Battistini, B.: Inhalation toxicology of urban ambient particulate matter: acute cardiovascular effects in rats, Res. Rep. Health Eff. Inst., 104, 5-54, 2001. von der Weiden, S.-L., Drewnick, F., and Borrmann, S.: Particle Loss Calculator - a new software tool for the assessment of the performance of aerosol inlet systems, Atmos. Meas. Tech., 2, 479-494, https://doi.org/10.5194/amt-2-479-2009, 2009.

Wang, D., Kam, W., Cheung, K., Pakbin, P., and Sioutas, C.: Development of a Two-Stage Virtual Impactor System for High Concentration Enrichment of Ultrafine, $\mathrm{PM}_{2.5}$, and Coarse Particulate Matter, Aerosol Sci. Technol., 47, 231-238, 2013.

Wang, W., Shi, C., Yan, Y., Yang, Y., and Zhou, B.: Ecotoxicological bioassay of atmospheric fine particulate matter $\left(\mathrm{PM}_{2.5}\right)$ with Photobacterium Phosphoreum T3, Ecotox. Environ. Safe., 133, 226-234, 2016.

Water quality: Determination of the inhibitory effect of water samples on the light emission of Vibrio fischeri (Luminescent bacteria test) - Part 1: Method using freshly prepared bacteria, ISO 11348-1:2007, Geneva, Switzerland, 2007.

Zhao, Y., Bein, K. J., Wexler, A. S., Misra, C., Fine, P. M., and Sioutas, C.: Field evaluation of the versatile aerosol concentration enrichment system (VACES) particle concentrator coupled to the rapid single-particle mass spectrometer (RSMS-3), J. Geophys. Res.-Atmos., 110, D07S02, https://doi.org/10.1029/2004JD004644, 2005. 